\title{
La interfaz: extensión del cuerpo o espacio para la comunicación. Metáforas que se traslapan ${ }^{1}$
}

\author{
The interface: Body Extension or a Space to Communication. \\ Metaphors that Overlap
}

\begin{abstract}
Resumen
El artículo parte por reconocer las interacciones que establece el ser humano en distintos entornos; distingue al tercer entorno como espacio en donde los sujetos experimentan diversas actividades cotidianas, mediadas por las TIC que han generado transformaciones sociales. En el tercer entorno se asienta la interfaz, objeto de las reflexiones plasmadas en este espacio. En la primera parte de este texto se muestra la necesidad de precisar qué es la interfaz, entonces, la construcción colectiva del concepto se convierte en una provocación. Luego, se recorre el origen y la evolución del concepto, desde la década del sesenta hasta la actualidad. Se concluye que la comunicación es reconocimiento, no obstante se advierte que los lenguajes virtuales, las narrativas y los conocimientos pueden convertirse en otras formas de exclusión y de marginación que deben ser objeto de una profunda reflexión académica, en beneficio del avance democrático de las culturas.
\end{abstract}

Palabras clave: Interfaz, tercer entorno, TIC, información, comunicación, cultura.

\section{Abstract}

This article begins recognizing the interactions set up by human beings at different environments. It points out the third environment as the space where subjects experience different daily routines mediated by ICTs which have created social transformations. The interface is based in the third environment and is the matter discusses here. In the collective construction of the concept is a provocation. Then, it is explained the origin and evolution of the concept from 60's to current days. It is conclude that communication is acknowledgement; however, it is advice that virtual languages, narratives, and knowledge can become in other ways of exclusion and marginalization that must be the subject of a thoughtful academic consideration which benefit the democratic advance of cultures.

Keywords: Interface, third environment, ICTs, information, communication, culture.

Recibido: 1 de abril de 2014, evaluado: 14 de abril de 2014, aprobado: 2 de junio de 2014

1 Artículo de revisión sobre el concepto de Interfaz, resultado de los debates del Grupo de investigación Interfaz, en el marco del curso orientado por Martín-Barbero y las investigaciones desarrolladas en este grupo. 
$\mathrm{E}$ 1 ser humano contemporáneo establece interacciones en diversos entornos: naturales y virtuales; estos últimos se encuentran sujetos al desarrollo tecnológico. Cada entorno ofrece unas dimensiones espaciales y temporales que lo caracterizan. En este escrito nos ubicaremos en el tercer entorno, tal como lo ha denominado Javier Echeverría (2001), porque precisamente es aquí donde se asienta la interfaz, objeto de las reflexiones del grupo de trabajo interfaz.

Hoy, en el tercer entorno, espacio social que se une a los otros dos - naturaleza y ciudad- los sujetos experimentan, realizan, diversas actividades de la vida cotidiana, mediadas por las tecnologías de la información y de la comunicación que, desde su aparición, han generado significativas transformaciones sociales. Estas tecnologías han permitido la configuración de un nuevo espacio y un nuevo tiempo en la sociedad informacional que, además, "integran al mundo en redes globales de instrumentalidad” (Castells, 1998, p.12).

En consecuencia, distinguir a la sociedad como "sociedad informacional", tal como la denomina Castells (2002), es reconocer la constitución de un nuevo paradigma tecnológico:

[...] en el que todos los procesos de la sociedad, de la política, de la guerra, de la economía pasan a verse afectados por la capacidad de procesar y distribuir energía de forma ubicua en el conjunto de la actividad humana (p. 2).

Ahora, cuando se hace referencia a la sociedad del conocimiento, el debate desde las ciencias sociales se centra en las transformaciones culturales que se experimentan en las últimas décadas. Por tanto, esta sociedad, como cualquier otra, requiere de un espacio y un tiempo para desarrollarse. En este caso nos centraremos en el espacio tecnológico, en ese entorno donde se encuentran ubicadas las tecnologías que rodean la vida cotidiana, que nos conectan a un nuevo espacio social en el cual establecemos diversas interacciones (Echeverría, 2001).

Pero, ¿cómo se realizan esas interacciones entre el ser humano y las Tecnologías de la Información y de la Comunicación? Se inician desde el momento en que una persona tiene acceso a un computador conectado a la red Internet. Este hecho desencadena una serie de procesos de interacción que se hacen posibles a través de la interfaz: "un dispositivo capaz de asegurar el intercambio de datos entre dos sistemas" (Scolari, 2004, p. 39), un puente que permite la comunicación entre ellos. No obstante, este concepto no se limita a un artefacto o a un proceso, el vocablo transgredió los límites del universo semántico informático para invadir otros territorios discursivos, desde el diseño hasta el marketing.

Por consiguiente, cuando se habla de interfaz, se observa la necesidad de precisar a qué se está haciendo referencia. Es esencial evitar el uso indiscriminado de los términos como virtual, entornos virtuales, ciberespacio, interfaz entre otros. De ahí que se haya planteado el interrogante: ¿qué es la interfaz?, porque de acuerdo con las respuestas que emerjan, es posible identificar las tendencias opuestas que generan y sitúan las discusiones a propósito del tema. En este sentido, cabe señalar que algunos consideran la interfaz de forma instrumental ${ }^{2}$, pero a la vez reconocen que, sin los instrumentos requeridos, no sería posible la interacción. Otras posiciones asumen la interfaz como mediadora de relaciones y se centran en los modos como se generan los nexos entre persona y máquina ${ }^{3}$, sin desconocer que la interacción con los instrumentos depende de cada usuario: cómo la entiende, cómo la usa, para qué la usa; es decir, "alguien necesita hacer algo" en un entorno virtual y lo usa, de acuerdo con sus conocimientos, hasta obtener los resultados requeridos.

2 Estas tendencias fueron identificadas, inicialmente por Silvia Pérez, quien abrió el debate en la reunión del Grupo Interfaz, el día 5 de octubre de 2010.

3 La relación hombre-máquina fue abordada por Betty Martínez, Eliécer Pinto y Oswaldo Ramírez, durante la reunión en mención; en este punto se une María Isabel Noreña, además formula un interrogante: ¿qué tipo de investigación surge de aquí?

Polisemia No. 17, 55 - 69. La interfaz: extensión del cuerpo o espacio para la comunicación. Metáforas que se traslapan. Bogotá, ISSN: 1900-4648. Enero - junio de 2014 
Pero, la interfaz no se limita a una entidad virtual (Lévy, 1999), sino que abarca distintos niveles y distintas perspectivas. Las interacciones en la red del conocimiento se realizan en ciertas condiciones y generan diversas formas de relaciones. Por tanto, se reconoce desde esta perspectiva tanto el proceso como la mediación.

Desde otros ángulos, se asume la interfaz como información o comunicación; como generadora de procesos, mediadora en la construcción de conocimiento y de sentido, que propicia nuevas forma de leer y de escribir; como facilitadora del diálogo hombre-máquina, en el que influye el estado de ánimo del sujeto. También, se considera un campo transversal de conocimiento; se define en tal sentido, como el conjunto de métodos para lograr interactividad entre un usuario y una computadora. En consecuencia, se reconoce que el término interfaz se ha usado desde hace mucho tiempo, pero se ha fortalecido con el desarrollo de las nuevas tecnologías.

En conclusión, definir el concepto de interfaz es una provocación; este ejercicio implica una discusión abierta en la que participan distintas concepciones. Aunque para Scolari (2004) resulte inútil definirla, aclara que lo considera un "concepto-paraguas", que se: "adapta a cualquier situación, o proceso donde se verifique un intercambio o transferencia de información" (p. 44).

\section{De la definición al origen y evolución del término}

El término interfaz ha sido sometido a distintas interpretaciones, se ha integrado al discurso informático en cuyo contexto designa a un dispositivo, un artefacto material que permite el intercambio de datos entre dos sistemas, de allí que se observen diferentes concepciones. Pero, es necesario señalar que el concepto no se inaugura con la era informática, su historia la sitúa Scolari (2004) en las investigaciones científicas del campo de la hidrostática (hace más de un siglo).
Hacia 1964 , la interfaz se define como un artefacto material que permite el intercambio de datos entre dos sistemas; en 1969 se le considera como un dispositivo que garantiza la comunicación, entendida como intercambio de datos entre dos sistemas distintos. "Un ordenador un aparato periférico como la impresora, o un sistema informático y una red de comunicación" (Scolari, 2004, p. 40).

En términos de conexión hardware, la interfaz se concibe como el límite común entre dos sistemas, proyectado con el objetivo de especificar el tipo y la forma de señales que pasan entre ellos; en tal sentido se distinguen dos elementos característicos de este proceso: es un dispositivo hardware y facilita el intercambio bidireccional de información entre los sistemas.

En 1984 se da un giro a la definición de interfaz, debido a la aparición del primer computador personal con sistema operativo gráfico, basado en la metáfora del escritorio, cuya repercusión se proyectó en el universo semántico de la informática. El término pasa, entonces, a ser definido como dispositivo ubicado en el territorio del hardware, al universo inmaterial del software y de las interacciones con los seres humanos.

La interfaz ya no se considera como un dispositivo material que separa dos porciones de materia, sino como aquel elemento que permite la comunicación entre dos sistemas. En síntesis, en la década del ochenta se consolida la concepción de la interfaz como instrumento en el ámbito de la interacción persona-operador. En 1987, una de las gramáticas para operadores registra el concepto de interfaz humana como la suma de intercambios comunicativos (Scolari, 2004, p. 42).

En 1995 la interfaz se concibe como conjunto de reglas y de convenciones a través de los cuales un sistema de computación comunica con su operador. Aunque se mantiene la idea de intercambio de información, ya no se considera como dispositivo hardware, sino como un conjunto de procesos, normas y convenciones que permiten la comunicación entre el ser humano y las má- 
quinas digitales; entonces pasa a ser comprendida como: "una gramática de la interacción" entre el ser humano y la computadora. Del sustantivo interface al verbo "to interface", de la "interfaz" a "interfazar", acuñado por McLuhan (Scolari, 2004, p. 43).

Otro cambio que se registra frente al término interfaz es que pasa del ámbito científico a ser considerado como una superficie o lugar de la interacción entre dos sistemas diferentes, no necesariamente tecnológicos. En esta posición ubicamos la definición de López Islas que apunta a reconocer que la interfaz constituye una estrategia de comunicación que pretende facilitar la relación entre el usuario y la tecnología. Agrega que, como lo sugiere Laurel (1990), es una "superficie de contacto" entre dos seres diferentes (el ser humano y la máquina).

Aunque a Scolari no le interesa construir una nueva definición, hasta le parece inútil e invita a la deconstrucción, sí propone un recorrido por las distintas metáforas dentro del universo discursivo informático y su paso a otros ámbitos discursivos, para así nombrar nuevos procesos y componentes. Por eso reitera el autor que prefiere realizar una deconstrucción conceptual.

Para finalizar este aparte, se reconoce el carácter móvil de la interfaz, que dificulta su aprehensión, no permite encuadrarla; de ahí que la comparemos con aquella mención que realizó el maestro Martín-Barbero sobre las raíces móviles de la sociedad contemporánea, la incertidumbre como fantasma de la Modernidad, porque los modernos desplazaron el ser del centro y allí ubicaron al orden. Tal como lo sustenta Bauman, citado por Martín-Barbero (2009), al plantear el orden se identifica el "pensar con el ordenar, y éste con separar, clasificar y controlar” (p.10).

La nueva metafísica moderna pretendía salir del caos del orden primitivo para construir un orden social que le proporcionara seguridad. Pero, hoy, esos ideales fueron desplazados por la "modernidad líquida”, acuñada por Bauman (2008), cuya fluidez implica que no se conserve fácilmen- te la forma; los líquidos no se fijan a un espacio, ni a un tiempo. Así, la interfaz nos permite fluir, desplazar con facilidad, brotar, manar y ¿por qué no exudar?

\section{El concepto de interfaz y sus relaciones}

La finalidad de configurar el concepto de interfaz, conocer su origen y evolución no tiene otro propósito que el de explicar, darle sentido, situarnos ante éste como dispositivo generador de procesos que intervienen cada vez más en las actividades cotidianas del ser humano contemporáneo. Por tanto, "hoy vemos emerger una generación cuyos sujetos no se constituyen a partir de identificaciones con figuras, estilos y prácticas de añejas tradiciones que definen la cultura sino a partir de la conexión-desconexión (juegos de Interfaz) con los aparatos" (Martín-Barbero, 2000, párr. 8).

A partir de la discusión que suscitó definir el concepto de interfaz, emergieron diversas relaciones con el término, entre ellas se seleccionaron las siguientes interfaz-diseño, interfaz-comunicación, interfaz-información e interfaz-cultura. Iniciemos pues con el tejido de estas relaciones.

\section{Interfaz-diseño: metáfora de la interacción}

\section{Hoy en dia, el programa ha desaparecido; uno entra en el mundo de la pantalla del mismo modo que Alicia atravesó el espejo.}

Sherry TURKLEy (1997)

La interfaz digital es el dispositivo que le permite a un sujeto interactuar con la máquina, con

Polisemia No. 17, 55 - 69. La interfaz: extensión del cuerpo o espacio para la comunicación. Metáforas que se traslapan. Bogotá, ISSN: 1900-4648. Enero - junio de 2014 
la red y con otros sujetos. Además, "la interfaz gráfica implica la presencia de un monitor de ordenador o pantalla constituida por una serie de menús e íconos que representan las opciones que el usuario puede tomar dentro del sistema" (Lamarca Lapuente, s/f). Pero, vale anotar que el sujeto no está "interactuando" sólo con la máquina; en realidad, lo hace a través del diseño que ha elaborado un sujeto, el creador del dispositivo.

"El trabajo del diseñador de interfaz implica mejorar el ambiente de trabajo de las personas" (Kioskea.net, s/f). Para ello son necesarios dos componentes: la eficiencia, que implica la implementación de soluciones apropiadas para el uso de los productos, además de las intenciones del diseñador; y la utilidad, que se refiere a la adecuación del producto con las capacidades del usuario.

Entonces, el diseñador de Interfaz debe trabajar con todo aquel que esté involucrado en el proceso de diseño de la empresa, para mejorar el ambiente de trabajo del personal o mejorar la ergonomía de los productos o el sitio Web de la compañía (Kioskea.net, s/f).

Los avances de la tecnología han permitido pasar de una interfaz que requería de un usuario altamente calificado a la interfaz que se esconde detrás de los objetos virtuales que la interpreta y que simula una realidad más cercana al sentido cognitivo del usuario, uno no especializado.

Mientras se robustecen las simulaciones logradas a través del ordenador en un entorno digital con las dimensiones propias de la virtualidad, se crean interfaces gráficas que organizan y enlazan la información por medio de íconos interactivos o imágenes de representación perceptual (ya no tan abstractas), como características propias de las tendencias del momento.

Uno de los ideales de los diseñadores de interfaz es simplificar el uso de los computadores para usuarios de todo tipo y no sólo para los expertos; por ello:

se ha convertido en una práctica habitual utilizar metáforas visuales por medio de la llamada
Interfaz gráfica de usuario (IGU o GUI en inglés) para que el usuario interactúe y establezca un contacto más fácil e intuitivo con el ordenador (Lamarca Lapuente, s/f).

La metáfora se constituye en un dispositivo cognitivo potente: "que modela la percepción, el pensamiento y las acciones cotidianas de las personas" (Scolari, 2004, p. 105). En el ámbito de lo digital cuando se mencionan las metáforas de interacción, se hace referencia a: "la metáfora del escritorio, que fue difundida con el sistema operativo Macintosh a partir de 1984" (Scolari, 2004, p. 106). La aplicación de esta metáfora permitió la evolución tanto de la interacción entre el hombre y las máquinas, como de los entornos de interacción, es decir, el escritorio. Pero, a la vez le impuso barreras a la expansión de las formas de interacción.

Entonces, la interfaz, en su relación estrecha con el diseño, se puede analizar desde tres aspectos: la interfaz vista como hardware, en donde según Scolari, dos sistemas diferentes se conectan físicamente para intercambiar datos, utilizando los dispositivos que facilitan esta función. Levy distingue estos componentes como aquellos elementos tangibles que conforman las máquinas o recursos físicos, que intercambian datos (board, integrados, memorias, discos duros, cables, pantallas, teclados, ratón); son los elementos que intervienen en estos procesos o relaciones gracias a impulsos eléctricos que se ven reflejados en códigos significantes para el usuario; por ejemplo, cuando a través del computador se dan indicaciones a la impresora para que genere un resultado.

Ahora, en la interfaz orientada al software se determinan espacios de encuentro entre el ser humano y los componentes lógicos que hacen posible la realización de tareas. Aquí se interpretan los impulsos eléctricos, los cuales entregan datos acerca de procesos y herramientas de control, observados habitualmente en la pantalla.

Entonces, aparecen los iconos, que contienen leyendas explicativas y menús que permiten la personalización del espacio o de las formas digitales con los que se interactúa o interviene, para 
producir un contexto y situaciones que resuelven necesidades específicas del usuario.

Por tanto, tal como lo expresa Lamarca Lapuente: "una buena Interfaz requiere de poco esfuerzo por parte del usuario, simplicidad y funcionalidad”. Es así como:

El diseñador de interfaces debe facilitar y simplificar el acceso y los recorridos de los usuarios. A menudo se usa la metáfora del viaje o del camino a recorrer y se presentan iconos o símbolos de Interfaz y otros dispositivos que tienen que ver con las señales utilizadas en mapas, urbanismo o arquitectura (Lamarca Lapuente, s/f).

La interfaz de software-hardware establece un puente entre la máquina y las personas, permitiendo a la primera procesar la orden y al sujeto entender el código binario traducido en información legible; es decir, origina de manera natural diálogos y acciones netamente imprevisibles, espacios que se diseñan con el fin de interpretar e interactuar, escenarios que buscan ser usables.

La interfaz de usuario traducida en íconos es entonces el medio a través del cual se interactúa con la máquina que, normalmente, suele ser fácil de entender y de operar. De esta manera, se reconoce que: "las tecnologías, para ser usadas efectivamente, requieren ser transparentes" (López Islas, 1997, párr. 2).

Cuando la metáfora sale bien, no se nota, y el dispositivo del como si, se fosiliza, o mejor se naturaliza y pasa desapercibido.

Jorge LuIS Borges ${ }^{4}$

En conclusión, es posible observar cómo en el campo tecnológico las herramientas han cambiado, gracias a la inteligencia humana que, a través de los descubrimientos, ha podido suplir parte de sus necesidades. Por eso, ajustamos diariamente la máquina a nuestro entorno mediante el uso y la aplicación de los elementos distribuidos en el escritorio, lugar donde se transformó nuestra realidad instrumental, la que incide en los procesos de interacción mediante el diálogo protocolario, utilizando la ventana, el aviso, la imagen, entre otros recursos.

Finalmente, la metáfora espacial se convierte en el escenario propicio para la interactividad entre el usuario y la máquina en relación con el software; dicha interactividad se ve mediada de acuerdo con la experiencia, el gusto y el estado de ánimo del usuario.

\section{Interfaz-información:}

\section{de la información a la comunicación. Del repositorio a la interacción}

En este eje se plantea que una primera relación entre la interfaz y el manejo de la información puede establecerse a partir de la aparición de las primeras formas escritas, ${ }^{5}$ tanto pictóricas como arquitectónicas. Después, con la aparición de los alfabetos, la generación de libros y la construcción de las bibliotecas, los textos se organizan y se clasifican para su consulta, convirtiéndose en las fuentes del saber, en ellos se depositan la información y el conocimiento. Posteriormente, con la invención creativa de la enciclopedia, se ordena el conocimiento a partir de temas, datos e informaciones que maneja el ser humano en la construcción de los distintos ámbitos del saber, sobre la base de una cultura de elite.

Si nos permitimos dar un salto - pasamos de un hipervínculo a otro- de la enciclopedia al tema de la sociedad de la información, entonces aparecen diferentes reflexiones, que ya se perfila-

4 Citado por Scolari, 2004, p. 34.

5 Se entiende aquí la escritura en sentido amplio.

Polisemia No. 17, 55 - 69. La interfaz: extensión del cuerpo o espacio para la comunicación. Metáforas que se traslapan. Bogotá, ISSN: 1900-4648. Enero - junio de 2014 
ban en el siglo XIX y que además guardan relación con el desarrollo de la tecnología y su vinculación con diferentes formas de comunicación. Como lo expresa Mattelart, la "liberación de los flujos" es el resultado de la: "libre comunicación del pensamiento y de las opiniones" (Benassini, 2005, p. 25).

El manejo de datos y de información cuantificada, asociados con la tecnología, suscitan la creación de máquinas capaces de simular los sentidos y sus razonamientos, con base en la construcción de ecuaciones y diferentes operaciones matemáticas. Hasta que, con la aparición del tríodo en 1906, la comunicación electrónica abre el camino a toda una gama de posibilidades.

En consecuencia, de esta relación entre información y tecnología surge un tercer elemento importante: el lenguaje, con sus distintas expresiones. Pero, no se llegó a imaginar el alcance que tendría el uso y aplicación de las nuevas tecnologías en las formas comunicacionales. Ya lo sugiere Mattelart:

Un pensamiento que entreteje el enlazamiento del globo tanto con las redes técnicas -el telégrafo y el cable submarino- como con las redes ciudadanas que surgen durante la segunda mitad del siglo XIX al amparo del reconocimiento de las libertades de prensa, expresión y asociación (Benassini, 2005, p. 32).

Entonces, convergen algunos elementos que van a caracterizar la construcción del concepto de "sociedad de la información", la cual está determinada por:

El paso de una economía de producción a una economía de servicio; la preeminencia de la clase profesional y la técnica; la nueva centralidad adquirida por el conocimiento teórico como una fuente de innovación y formulación de políticas públicas; anticipar el futuro y el auge de una nueva tecnología intelectual, dirigida hacia la toma de decisiones (Benassini, 2005, p. 35).

El desarrollo de las nuevas Tecnologías de la Información y las Comunicaciones ha generado nuevas posibilidades en el manejo de la información, pero el concepto de sociedad de la información se ha rezagado. No obstante, vale la pena recordar que la expresión fue:

acuñada por la Unión Europea, concretamente por su comisario de Tecnologías de la Información, tras el éxito de lo que Al Gore y Bill Clinton llamaron, con una metáfora muy acertada, 'las autopistas de la información' para referirse a nuevas tecnologías, especialmente a Internet, que, como las redes de carreteras, transportan información (Echeverría, 2001, párr. 2).

Para concluir, desde el punto de vista institucional, la Unesco ha retomado el tema en su agen$\mathrm{da}$, lo ha insertado en sus actividades, incluida la investigación. Es así como se generan respuestas de toda índole ante un tema de por sí polémico, tales como las críticas reiteradas que enmarcan la relación Norte-Sur; la repetitiva mención de la brecha, que ahora se volvió digital; la participación de la ciudadanía; la generación de conocimiento, entre otras.

Interfaz: una dinámica entre la aplicación y la apropiación

En términos prácticos, el interfaz y la información han generado muchas e innovadoras dinámicas que parten de la apropiación de la información establecida desde las configuraciones de software y hardware, hasta el uso de la Internet y las redes de información. En ese sentido, es importante caracterizar el paso de la Web 1.0 a la Web 2.0, que ha significado el cambio de modelo o paradigma. No se trata de ver la Internet como un medio de comunicación, sino como una posibilidad de interacción y construcción de nuevas culturas, las culturas digitales.

La Web 1.0 consistía en sitios (repositorios) donde se colocaba información y el usuario entraba a recibirla. En la Web 2.0 la información es colaborativa. No pertenece a una sola persona, sino a una comunidad. Basta ver cómo Wikipedia es 
una enciclopedia construida a millares de manos. El texto escrito, en un sentido unívoco, perdió su preponderancia. El hipertexto se impone ahora, no sólo como forma de vincular o generar links a diferentes niveles de información, sino como formas de información planteadas desde lo sonoro, la imagen fija o en movimiento, diseños, graficaciones, ilustraciones y cientos de posibilidades de combinar narrativas y discursos.

Una forma irónica de ver la barrera que ponemos para acceder a las posibilidades de la información con las nuevas tecnologías puede verse en: "Soporte Técnico Edad Media"6, video en el que un monje acostumbrado a los pergaminos pide ayuda para entender cómo se maneja el libro. Ejemplo que se complementa con "Book" , video en el que se explica, desde el lenguaje de las nuevas tecnologías, el uso mágico y novedoso del gran invento llamado libro.

Las posibilidades que emanan del uso adecuado de las tecnologías en el manejo de la información radican en la participación de las nuevas dinámicas que nos sitúan en planos definidos por las siguientes preguntas: ¿Cómo buscar la información? ¿Cómo validarla? ¿Cómo distribuirla? ¿Cómo potenciarla? Carlos Scolari nos ofrece un nuevo piso teórico para entender las posibilidades de las TIC con "Hipermediaciones, elementos para una teoría de la comunicación digital en interactiva”. También George Siemens nos ofrece con su teoría, sobre conectivismo, modelos educativos colaborativos en el sentido de la construcción del conocimiento y Thomas Davenport muestra el modelo de la "ecología de la información” para la construcción de sistemas de circulación de contenidos.

Aunque el tema puede tratarse con humor, al graficar a través del hipertexto la distancia que las generaciones no digitales crean para no acer- carse a las posibilidades de las TIC, en Sobre la ignorancia informática" " un oficinista encuentra un uso creativo de la unidad de CD como soporte para su café de la mañana. Por su parte, en $E l$ mejor monólogo de informática de la historia ${ }^{9}$, un comediante representa un monólogo genial sobre la conexión de los imaginarios culturales con respecto a los nuevos lenguajes de las TIC y la información gráfica que genera el interfaz; finalmente, en Nuevas tecnologias "vaya semanita", un confesionario tecnificado muestra las diferentes posibilidades de la confesión en la Iglesia Católica.

\section{Las incertidumbres de la comunicación}

¿Cómo convivir pacificamente en un universo donde todo el mundo lo ve todo y donde las diferencias son más visibles y menos negociables? Esta pregunta formulada por Dominique Wolton (2010) nos sitúa en la reflexión sobre la interfaz como elemento "facilitador" en los procesos de interacción. Por tanto, si tomamos en cuenta que la interacción genera y produce sentidos, ¿en qué medida entonces la cultura actual se construye a partir de las relaciones entre el hombre y la máquina?, ¿la adopción de la interfaz supera esta inicial relación y se convierte en facilitadora de procesos de comprensión y diferenciación entre informar y comunicar?

La discusión es de antaño, pero quizás sigue siendo actual cuando se retoma el sentido original de que comunicar es convivir. En efecto, al igual que Wolton, muchos nos preguntamos si la aparición de la interfaz, con todos sus encantos y posibilidades, ha hecho perder de vista una advertencia planteada por los críticos del determinismo tecnológico:

\footnotetext{
6 Soporte Técnico en la Edad Media. (2007). Catálogo en Línea. [Archivo de Video].

Popularlibros.com- Book. (2010). [Catálogo en Línea. [Archivo de Video].

8 Sobre la ignorancia informática. (2005). Catálogo en Línea. [Archivo de Video].

9 El mejor monologo de informática de la historia. Catálogo en línea. [Archivo de Video].
}

Polisemia No. 17, 55 - 69. La interfaz: extensión del cuerpo o espacio para la comunicación. Metáforas que se traslapan. Bogotá, ISSN: 1900-4648. Enero - junio de 2014 
La comunicación se encuentra amenazada por otras dos ideologías: el individualismo, o sea, la reducción del a comunicación a la expresión y a la interactividad. Y el comunitarismo, o sea, la marginalización de la cuestión de la alteridad y la posibilidad de encerrarse en los espacios virtuales (Wolton, 2010, p. 31).

Sin pretender ser puristas, Wolton (2010) y otros críticos recuerdan una realidad rampante de nuestros pueblos, la misma que señala Jesús Martin-Barbero cuando hace un llamado fuerte a las sociedades contemporáneas a que la mediación tecnológica sea facilitadora de procesos relacionales más humanos:

El lugar de la cultura en la sociedad cambia cuando la mediación tecnológica de la comunicación deja de ser meramente instrumental para espesarse, densificarse y convertirse en estructural, pues la tecnología remite hoy no sólo a la novedad de unos aparatos sino a nuevos modos de percepción y de lenguaje, a nuevas sensibilidades y escrituras. Lo que la trama comunicativa de la revolución tecnológica introduce en nuestras sociedades no es tanto una cantidad inusitada de nuevas máquinas sino un nuevo modo de relación entre los procesos simbólicos — que constituyen lo cultural-y las formas de producción y distribución de los bienes y servicios (Martín-Barbero, 2002, párr. 3).

La interfaz como metáfora de apropiación tecnológica de dispositivos nos invita hoy más que nunca a la acción dialógica desde una comprensión no fácil de la diversidad cultural, de los encuentros y desencuentros de saberes, de la nueva configuración de paisajes culturales, de esos "saberes-mosaico", como lo expresa MartínBarbero (2002), que "en forma de información, circulan por la sociedad” (párr. 6).

De hecho, una reflexión sobre la cultura digital conduce a mirar plataformas y dispositivos electrónicos precisamente como esos espacios que trasladan a los sujetos comunicativos de un ambiente a otro sin que necesariamente se encuentre creando vínculos "humanizados"; pero, ¿quién puede afirmar que por ello no se produce otro tipo de interacciones relacional vinculante y quizás más liberadora para el hombre contem- poráneo que puede, gracias a la interfaz, "perder" su corporeidad y movilizarse más "liviano"? Es quizás una pregunta a la que la Antropología cultural y la Sociología contemporáneas han dado respuestas.

\section{Interfaz:}

\section{encuentros y desencuentros}

Fabio Pasqualetti, profesor de radioy de Nuevas Tecnologías en la Facultad de Comunicación de la Pontificia Universitá di Roma, propone pasar de los lugares de encuentro, al encuentro de las personas (2007, p. 2). Por tanto, el lugar de encuentro tradicional conocido como espacio público (la casa, el supermercado, el templo, las autopistas, los vehículos para el transporte público, etc.) en cierto modo, se "deshumaniza" — desde una visión tradicional - pero invita, según el autor, a generar los encuentros interpersonales, superando los límites de la geografía.

Por tanto, la interfaz, entendida como ese espacio o fragmento de espacio, nos remite irremediablemente al concepto del no-lugar (propio de la era posmoderna), es decir, a aquel territorio que trasciende y, de alguna manera, supera la espacialidad delimitada, física y material, para ofrecerse como escenario de intercambio simbólico.

En ese mismo sentido, se piensa no sólo en el no-lugar, sino en el más allá del lugar, oltre il luogo, a la manera de Meyrowitz (1995). De esta manera, se amplía la mirada hacia lo que se entiende como situaciones comunicativas o informativas. Cabe recordar que las situaciones generalmente son definidas en términos de comportamientos en lugares físicos. Y a menudo el interés por los contenidos en algunos estudiosos está ligado a los ambientes. Por ejemplo, para George Gerbner (1976), la televisión es un ambiente simbólico en el que vivimos, un ambiente que cultiva una específica visión del mundo.

Pero, a estos investigadores lo que les interesa mirar es, sobre todo, la imagen de la realidad 
representada por los ambientes televisivos. Sobre este aspecto habría que profundizar desde los estudios sobre usos y gratificaciones.

Sin embargo, habría que plantearse una reflexión similar si pensamos en los medios electrónicos como la relación entre ambientes preexistentes. Meyrowitz (1995) va más allá, presentando la posibilidad de que los medios electrónicos creen nuevos ambientes sociales que dan forma a comportamientos y a productos comunicativos nuevos, a "otras" representaciones. He aquí entonces la invitación a mirar nuevos paisajes mediáticos y nuevos paisajes sociales y culturales.

Entonces, se ha afirmado que las situaciones sociales son producto también de configuraciones mediáticas diferentes y, en algún sentido, transgresoras del "dónde", fuera del lugar, más allá del lugar. Las situaciones creadas desde la interfaz proponen dinámicas de interacción, desde nuevas comprensiones del sentido, desde nuevos perfiles de los sujetos que se comunican - por tanto problematiza la cuestión de identidad- y sugiere además una forma de reconocimiento, entendiendo por éste no sólo la visibilización de los sujetos preexistentes, sino la posibilidad de descubrir y dar cuenta de nuevas formas de ser y de estar en el mundo. El desafío está allí: sin aspavientos ni miedos habrá que indagar sobre qué tipo de seres humanos son los que surgen hoy, en esa interacción con la interfaz. Un reconocimiento que casi no admite el re, del re-conocerse, sino casi el asombro que suscitará el conocer otras situaciones culturales a partir de otros ambientes virtuales que resultarían asombrosos y posibles, si damos el paso hacia el encuentro donde el no vernos y no tocarnos nos causa temor, pero, al mismo tiempo, nos da la posibilidad de no negarnos.

Quizás la interfaz nos brinda la posibilidad de dar espacio a aquel o a aquellos que el "donde tradicional" no ha permitido en categorías tales como exclusión-inclusión; estratificación socio económica en alto-medio-bajo; masculinidadfeminidad, etc.
En consecuencia, como se evidencia en las relaciones expuestas en este escrito a propósito de la interfaz, se partió, en primera instancia, del diseño, para pasar a los sentidos de la información en su contexto, luego a la comunicación y ahora finalizamos con el abordaje de la relación interfaz/cultura, en la que convergen dos posturas aparentemente contradictorias: por un lado, la de su comprensión como un dispositivo que se convierte en una extensión del cuerpo y, por el otro, la de un elemento que genera procesos de comunicación, de construcción de sentidos, de desterritorialización, que vuelve cotidiana la noción de atemporal y cuestionan el reconocimiento entre los sujetos. Pasemos a ese plano.

\section{Interfaz-cibercultura:} metáfora de la realidad. De la identidad en red al cuerpo interface

\author{
Nos preguntamos si la adicción a la máquina, de la \\ subjetividad contemporánea no estará amenazando \\ la misma esencia del sujeto.
}

FÉLIX GUATTARI (1996)

Antes de adentrarnos en la reflexión sobre la cibercultura, es preciso realizar un breve recorrido por el complejo concepto de cultura, desde la concepción que tradicionalmente se le ha dado en las ciencias sociales. Clifford Geertz (1990) afirma que se entiende al humano como un animal inserto en tramas de significación que él mismo ha tejido y, por tanto, la cultura es esa urdimbre que:

denota un esquema históricamente transmitido de significaciones representadas en símbolos, un sistema de concepciones heredadas y expresadas en formas simbólicas por medios con los cuales los hombres comunican, perpetúan y desarrollan su conocimiento y sus actitudes frente a la vida (p. 20).

Polisemia No. 17, 55 - 69. La interfaz: extensión del cuerpo o espacio para la comunicación. Metáforas que se traslapan. Bogotá, ISSN: 1900-4648. Enero - junio de 2014 


\section{Cultura virtual o virtualidad real}

La cultura está constituida por flujos de comunicación y ésta, a su vez, por la producción e intercambio de signos. Por tanto, la realidad es su representación simbólica. Los humanos siempre hemos actuado a través de esta construcción simbólica de nuestra realidad. Toda la interpretación del mundo necesariamente ha pasado por este sistema, creando un entorno simbólico que podemos definir como realidad virtual. Sin embargo, la virtualidad a la que se hace mención en este análisis se refiere primordialmente al fenómeno tecnológico creado por la comunicación electrónica interactiva y al cual M. Castells (1998) denomina virtualidad real entendida como:

Un sistema en el que la misma realidad (esto es, la existencia material/simbólica de la gente) es capturada por completo, sumergida de lleno en un escenario de imágenes virtuales, en el mundo de hacer creer, en el que las apariencias no están sólo en la pantalla a través de la cual se comunica la experiencia, sino que se convierte en la experiencia (p. 406).

Finalmente, se considera que el rasgo más importante de la cibercultura es que captura dentro de sus dominios la mayor parte de las expresiones culturales en toda su diversidad. En este sentido, estaríamos hablando de una metacultura que homogeniza y borra las fronteras culturales, creando un plano global en el cual la riqueza de la diversidad habrá desaparecido. Las expresiones culturales al ser intercambiadas, a través de la Comunicación Mediada por Computador (CMC), crean un supertexto en el cual la lógica de la temporalidad (pasado, presente y futuro) se comprime, transformando las manifestaciones de la cultura por el carácter inmediato y práctico que adquieren, se suscita una desterritorialización simbólica. El sistema CMC no crea una nueva cultura, sino que abarca y fusiona todas las expresiones culturales, uniformando y redefiniendo sus sentidos.

Las tecnologías de la comunicación y la información poseen un poder extraordinario para distribuir información, sin límites temporales ni espaciales. Internet constituye un sistema de interconexión entre un número ilimitado de individuos, en un tiempo selectivo, a escala global y representa actualmente la base tecnológica de la forma organizativa que caracteriza a la era de la información: la red.

\section{El ciberespacio: espacio de flujos}

En esta transformación de los universales de la cultura, uno de los más importantes es la pérdida de la noción del espacio en donde descansan categorías fundamentales, como la territorialidad, la alteridad y la corporeidad. A esta nueva clasificación de espacio Edward Soja (citado por Mayans, 1989) la llama "geografías postmodernas" e implica la construcción imaginaria de un elemento tan consustancial a la identidad humana que no es posible prescindir de él y por eso es necesario convertirlo en metáfora.

\section{El tiempo}

El tiempo cultural es vital en el sentido de la orientación histórica de lo colectivo, esquema que es transmitido de generación en generación; pero que cobra sentido en la medida en que las nuevas generaciones tengan la posibilidad de contrastarlo con su propia experiencia existencial, para adecuarlo a ese nuevo marco de referencia por su propia práctica social. Las clásicas nociones de tiempo (mítico, lineal, cronológico) han quedado transformadas en la estructura de la sociedad-red. Castells lo denomina "tiempo atemporal" (2002, p. 468), aludiendo a una negación del tiempo en el desarrollo de las tecnologías de la comunicación. Siendo uno de los cimientos de la cultura, la transformación de la noción de tiempo es, tal vez junto con la del espacio, la más importante variación de la realidad humana por efecto de la CMC. 


\section{Transformación y redefinición de las identidades en la red}

Las tecnologías electrónicas de información y comunicación ya no se restringen únicamente al registro y distribución de contenidos representacionales, sino que producen por sí mismas nuevas formas de articulación de enunciación individual y colectiva, a lo que Guattari llama "aparatos colectivos de subjetivación" (1996). Sin embargo, este tipo de tecnologías contemporáneas han desarrollado niveles tan avanzados de operatividad, en ensamblaje con el humano, que parecería que han llegado a convertirse, en sí mismas, en sus interlocutoras válidas.

Los cambios en las identidades han sido un proceso histórico permanente, aunque la configuración de esas mutaciones se ha establecido en todos los casos bajo los mismos parámetros espacio-temporales. Más allá de la consideración sobre el fin de las identidades fundamentalistas y monolíticas que dieron paso a las actuales, supuestamente fragmentadas y saturadas, (Gergen, 2002, p. 26), las preguntas giran en torno a la posibilidad de interpretación de las subjetividades actuales y futuras y sobre los nuevos parámetros en los que se depositarán su producción y significación, teniendo en cuenta que el desarrollo tecnológico es un fenómeno irrefrenable, que se multiplica exponencialmente, pero que, cada vez más, va comprimiendo el mundo y la historia, porque ha demostrado su posicionamiento como preferencial mediadora de la interacción social, en espacios en donde el entorno natural tiende a coincidir con el entorno mecánico.

Tradicionalmente se ha aceptado que las identidades se han establecido sobre una percepción interna construida por acción de la experiencia, tanto colectiva como individual. Sin embargo, hemos visto cómo el proceso comunicativo CMC extraña los elementos experienciales directos de la acción comunicativa, creando ámbitos abstractos e imaginaros como suplencia inmediata para el intercambio. Pero, no solamente la ficción de estos entornos de la experiencia afecta el proceso comunicativo, sino también el contenido mismo del mensaje que desplaza la constitución interna de quien comunica.

En cuanto a las emociones, que han sido consideradas a través del tiempo factores primordiales de producción y significación de nuestra identidad, han quedado desplazadas a formas gráficas elementales - la reducción más extrema de la representación de la condición humana- convertidas en "emoticonos" (íconos simples que intentan significar de manera reducida los estados de ánimo de los interlocutores).

Es así como las tecnologías de la comunicación electrónica dibujan un nuevo paisaje social, constituido por grupos en busca de expresión, reconocimiento y estabilidad, a través de la sensación de presencia en redes o comunidades virtuales en las cuales tratan de estabilizar sus identidades en planos extremadamente difusos e inestables.

\section{El cuerpo interface}

Un elemento fundamental para el análisis de esta nueva cultura y sus repercusiones en resignificación de la identidad es la pérdida o la ausencia del cuerpo en la intercomunicación con los demás. Al parecer, la pérdida del espacio y el tiempo como categorías básicas de la cultura ha derivado en la ausencia del cuerpo en la CMC.

"El yo naturalmente, está corporeizado", afirma Giddens (1997, p. 76). La prefiguración de nuestro cuerpo nos vincula con otros, de una manera inicial y directa, éste se constituye como principio y fin de toda interacción humana. El cuerpo no es solamente una entidad, sino una experiencia constante del yo. Las expresiones del rostro y las posturas corporales proporcionan el contenido fundamental de esta contextualidad o indicialidad, condición de la comu-

Polisemia No. 17, 55 - 69. La interfaz: extensión del cuerpo o espacio para la comunicación. Metáforas que se traslapan. Bogotá, ISSN: 1900-4648. Enero - junio de 2014 
nicación cotidiana, generadora primordial de todo vínculo social.

El cuerpo real y práctico es suplantado por el cuerpo interface hombre-máquina, como generación de una nueva forma de encarnación, que se instaura desde una confluencia simbólica entre lo artificial y lo natural, lo virtual y lo real, donde el cuerpo se expande, se fusiona con la máquina, se complementa y se transforma. El cuerpo-interface es un cuerpo narrado. La comprensión de esta nueva forma de construcción de la corporeidad debe entenderse a luz de nuevas formas de interpretación: el cuerpo-prótesis. La constitución particular del interface consiste en imitar la misma estructura. Para Roseanne Stone, el cuerpointerface es una "estructura ausente de personalidad" (1996, p. 529) y es otra forma de describir esas nuevas y vagas formas de sentir que son los computadores, sensaciones que, por demás, aparecen seductoras.

Pensar el sujeto en la era de la información nos enfrenta a la pregunta por la constitución de la identidad en entornos descorporeizados, cuerpos en interface permanentemente, expuestos a intercambios, transcodificación y transubjetivación, transformando las maneras de estar en el mundo desde unas perspectivas que generen nuevas éticas y estéticas.

En consecuencia, se suscitan muchas inquietudes sobre la constitución humana, basada en estos nuevos sensorios de la alteridad y la subjetividad, construidos con la automatización de la interactividad y sobre el parámetro de un tiempo uniforme, en donde el tiempo real es un tiempo mundial. El cuerpo-interface (hombre-máquina) es el escenario de emergencia de una nueva forma de encarnación, en donde el cuerpo se expande, se complementa y se transforma, convirtiéndose también en metáfora.

Como corolario de todo lo anterior, podemos inferir un cambio inicial, pero significativo en las identidades, dado por el cambio en la estructura básica de la comunicación, con la cual tradicionalmente se habían reproducido los modelos culturales. Dentro de una dinámica de seducción absoluta, el fenómeno de la comunicación interactiva electrónica, siendo una realidad irrefrenable y que de manera contundente ha demostrado impactar los más importantes fenómenos socio-culturales, amerita ser analizado y pensado desde múltiples ángulos, aunque aquellos interesados siempre seremos tildados de "obsoletos".

No obstante, la transformación operada en la noción de espacio no se reduce sólo a este cambio de categorías. En un plano más profundo y determinante, lo que en nuestros días hemos empezado a ver es la transformación de la propia índole de los ordenadores lógicos de la mente humana, fenómeno posibilitado por la técnica contemporánea, introduciéndose con ello modificaciones o transmutaciones, paralelas y radicales, en la estructura epistémica y ontológica de sus tradicionales nociones y sus implicaciones en la constitución de los sujetos.

Desde otro ángulo, es visible su pertinencia epistemológica que, en tanto la razón tecnológica, comprime el espacio de las culturas, produciendo una homogeneización de las formas de percepción y de lenguaje, unas nuevas formas de sentir, de expresar, pero ante todo, de conocer.

La identidad, como una unidad psíquicoafectiva, descansa en gran medida sobre las representaciones que del mundo real se construyan y se fundamenta, como se dijo anteriormente, en un proceso cognitivo, cuya alteración afectará de una u otra forma todas las instituciones culturales, lingüísticas, ontológicas, éticas, políticas del entorno social general.

Por tanto, como idea de cierre, pero que abre nuevamente el debate sobre la cuestión que nos convoca: la comunicación es reconocimiento. No debemos perder de vista que los lenguajes virtuales, las narrativas y los conocimientos que se generan también se convierten en otras formas de exclusión y de marginación que deben ser el objeto de una profunda reflexión académica, en beneficio del avance democrático de las culturas. 


\section{Referencias}

Bauman, Zygmunt (2008). Modernidad líquida. México D. F.: F. C. E.

Benassini, Félix (2005). Orígenes del concepto sociedad de la información. En C. O. Islas (Coord.), Internet y la sociedad de la información. Quito: Ciespal.

Castells, Manuel (1998). La era de la información. Madrid: Alianza. Madrid: Areté

$$
\text { (2001). La galaxia Internet. }
$$

(2002). La dimensión Cultural de Internet. La sociedad del conocimiento: un nuevo paradigma tecnológico. Recuperado de http://www.uoc.edu/culturaxxi/esp/articles/ castells0502/castells0502.html

Echeverría, Javier (2001). Sociedad y nuevas tecnologías en el siglo XXI. Aula de Cultura virtual. Recuperado de http://servicios.elcorreo. com/auladecultura/javierecheverria1.html

El mejor monologo de informática de la historia. Catálogo en línea. [Archivo de Video]. Recuperado de www.youtube.com/ watch?v=H-ePzvCcYXk

Gergen, Kenneth (2002). El yo saturado. Dilemas de identidad en el mundo contemporáneo. Barcelona: Paidós.

Geertz, Clifford (1990). La interpretación de las culturas. Buenos Aires: Gedisa.

Giddens, Anthony (1996). Las consecuencias perversas de la modernidad. Barcelona: Anthropos.
Hernando, Almudena (2002). Arqueología de la Identidad. Madrid: Akal.

Islas C., O. (2005). Internet y la sociedad de la información. Quito: Ciespal.

Kioskea.net. (s/f). Diseñador de Interfaz. Recuperado de http://es.kioskea.net/contents/metiers-informatique/ergonome.php3.

Lacalle, Alberto (octubre de 2001). Importancia de una buena Interfaz. ¿Por qué es importante la Interfaz? Recuperado de http://albertolacalle.com/diseno-Interfaz.htm

Lamarca Lapuente, María Jesús (s/f). Interfaz gráfica. Hipertexto: El nuevo concepto de documento en la cultura de la imagen. Recuperado de http://www.hipertexto.info/documentos/ Interfaz.htm.

Lévy, Pierre (1999). ¿Qué es lo virtual? Barcelona: Paidós.

Levi-Strauss, Claude (1981). La Identidad. España: Pretil.

Madrid: Alianza.

(1989). Mito y significado.

López Islas, José Rafael (junio-agosto, 1997). Tecnologías de comunicación e identidad: Interfaz, metáfora y virtualidad. Dimensiones internacionales de la comunicación 7(2). Recuperado de http://razonypalabra.org.mx/ anteriores $/ \mathrm{n} 7 /$ rafa.htm

López Veneroni, Felipe (1997). La ciencia de la Comunicación. México D.F.: Trillas.

Polisemia No. 17, 55 - 69. La interfaz: extensión del cuerpo o espacio para la comunicación. Metáforas que se traslapan. Bogotá, ISSN: 1900-4648. Enero - junio de 2014 
Martín-Barbero, Jesús (2000). Dislocación del tiempo y nuevas topografías de la memoria. Recuperado de http://es.scribd.com/ doc/7578983/Dislocaciones-del-tiempo-ynuevas-topografias-de-la-memoriaw

(2002). Tecnicidades, identidades y alteridades. Revista Diálogos $N^{\circ} 64$. p. 8-23.

(2002a). Entre racionalidad y tecnicidad: tiempos y espacios no pensados. Grandes conferencias en la Facultad de Ciencias Humanas. Universidad Nacional de Colombia, Bogotá.

(2002b). La educación desde la comunicación. Bogotá: Norma.

(Septiembre, 2006). De incertidumbres e inciertas esperanzas: una meditación sobre el comunicar en medio de la tormenta. Presentado en Ciudadanías de la incertidumbre de Felafacs-Universidad Javeriana, Bogotá.

(2009). Nuestra excéntrica y heterogénea modernidadbarbero. Recuperado de http://revistaestudiospoliticos.udea.edu. co/index.php/estudiospoliticos/article/ viewFile/1401/1462

Mayans, Joan (s/f). Nuevas Tecnologías, viejas etnografía. Barcelona: Universidad de Barcelona.

Meyrowitz, Joshua (1995). Oltre il senso del luogo. Come i media elettronici influenzano il comportamento sociale. Baskerville: Bologna.

Moreno, Luciano (septiembre de 2005). Qué son las interfaces, las interfaces web y las interfaces gráficas. Recuperado de http://www.desarrolloweb.com/articulos/2171.php

Pasqualetti, Fabio (s/f). Cultura digital, un reto para la catequesis y la pastoral.
Recuperado de: http://www.misionjoven. org/04/06/329_5_14.html

Popularlibros.com- Book (2010). [Catálogo en Línea. [Archivo de Video]. Recuperado de http://www.youtube.com/watch?v=iwPj OqgvfIs

Scolari, Carlos (2004). Hacer clic. Hacia una sociosemiótica de las interacciones digitales. Barcelona: Gedisa.

(2008). Hipermediaciones, elementos para una teoría de la comunicación digital interactiva. Barcelona: Gedisa.

Sobre la ignorancia informática (2005). Catálogo en Línea. [Archivo de Video]. Recuperado de http://www.youtube.com/ watch? $=\mathrm{ca} 7 \mathrm{VyX} 6 \mathrm{~s} 7 \mathrm{f} 4$

Soporte Técnico en la Edad Media. (2007). Catálogo en Línea. [Archivo de Video]. Recuperado de: http://www.youtube.com/ watch?v=K654kfJy9ZA

Sperber, Dan (1988). El simbolismo en general. Madrid: Anthropos.

Touraine, Alain (1990). Crítica de la modernidad. México D.F.: F. C. E.

Turkle Y, Sherry (1997). La vida en la pantalla: la construcción de la identidad en la era de Internet. Barcelona: Paidós.

Virilio, Paul (1997). El cibermundo, o la politica de lo peor. Madrid: Cátedra.

Wolton, Dominique (2010). Informar no es comunicar. Contra la ideología tecnológica. Barcelona: Gedisa.

Zeraoui, Zidane (2000). Modernidad y postmodernidad. México D. 